
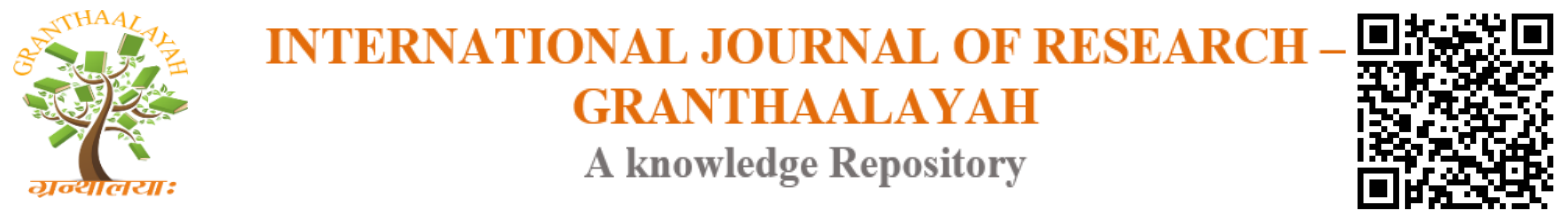

Social

\title{
A COMPARATIVE STUDY OF GIRL'S PHYSICAL SCIENCE PERFORMANCE BETWEEN CO-EDUCATIONAL AND SINGLE SEX SCHOOLS IN SWAZILAND
}

\author{
Kelly V. L ${ }^{1}$, Oloyede O. I *1 \\ ${ }^{* 1}$ Department of Curriculum and Teaching Faculty of Education University of Eswatini
}

\begin{abstract}
The major objective of the study was to compare the performance of girls studying physical science in single sex schools and those in co-educational schools. Three research questions were raised and one hypothesis formulated. The study adopted a cross-sectional survey research design using a sample of forty students' randomly selected from two single - sex and two co - educational schools from the Manzini region of Swaziland. Data was collected using the Swaziland General Certificate of Secondary Examination results and a 10 - item 5 - scale Likert type of questionnaire. Data was analyzed using the Statistical Package for Social Sciences (SPSS). T-test was used to test the hypothesis at 0.05 level of significance. The findings from this study showed that girls from single-sex schools perform significantly better in physical science than girls from co-educational schools. Social factors have the greatest influence on girl's physical science performance, while school management issues have the least influence. It was concluded that performance of girls in single-sex schools is significantly different from the performance of girls from co-educational schools and social factors have the greatest influence on the physical science performance of girls. It was therefore recommended that teachers in co-educational school should do everything possible to improve the performance of girls in their schools and teachers in both schools should provide guidance and counseling services in order to educate the girls on the effects of social factors such as peer pressure on their physical science performance.
\end{abstract}

Keywords: Comparative Study; Physical; Schools.

Cite This Article: Kelly V. L, and Oloyede O. I. (2019). "A COMPARATIVE STUDY OF GIRL'S PHYSICAL SCIENCE PERFORMANCE BETWEEN CO-EDUCATIONAL AND SINGLE SEX SCHOOLS IN SWAZILAND." International Journal of Research - Granthaalayah, 7(1), 373-382. https://doi.org/10.29121/granthaalayah.v7.i1.2019.1066.

\section{Introduction}

\section{Background and Setting}

There are perceived discrepancies in the performance of girls, studying physical science more especially when they are, in the same classrooms with boys. These problems have led to many studies in gender related topics, girl's achievement in science, studies in brain science, i.e. 
Neuroscience. Research has shown that girls in single sex schools out-perform their co-educational counterparts (Van Zyl.2011, Sullivan, Joshi, \& Leonard, (2011). Moreover, Oloyede (2010) argues that there is vast evidence in favour of single sex school, into improving the girl's academic achievements as well as promoting more positive academic aspirations. Various issues have been raised through numerous studies (Ozgur, 2014; Goldman, J.D. \& McCutchen, L. E., 2012; Stromquist ,2007) in relation to the differences in performance of girls studying physical science, it has been shown that, factors such as sex-role stereotypes, teachers attitudes towards girls, the perceptions that girls have about themselves, lack of female chemistry role models, social and cultural gender related factors, have resulted to problems in performance of the girls in physical science.

Eriba and Ande (2006) mentioned that the increased gap in terms of performance between girls and boys, in physical science have seen a great number of girls ignoring physical science in preference to arts and languages while the boys remain in the sciences. Moreover studies (Palkhe, Hyde \& Allison,2014; Oloyede, 2010) have shown that few girls choose to continue with physical science in subsequent level of education and others drop it in preference for study areas like biology in tertiary education. The neglect of physical science by most girls coupled with their poor performance in the subject has detrimental effects on their future when we consider that the government of Swaziland has passed a 2011 scholarship policy, which outlines and emphasize on awarding scholarship for only priority courses for those candidates who intend to pursue their studies in tertiary institutions, such as the university of Swaziland, the scholarship policy, show that the government of Swaziland is willing to provide scholarship to education, science, information technology, agriculture science and engineering students. Ssempala (2005) argues that girl's poor performance in physical science greatly limits their future career opportunities in areas such as, medicine, veterinary medicine, agriculture, food science, industrial chemistry and technology. It is essential to; study the performances of girls in physical science in both single gender and co-educational schools because physical science is linked to a wide range of disciplines.

Examination Council of Swaziland (ECOS) result database for years 2008-2012 showed that there is generally a poor performance in physical science. It also showed that many girls who study physical science are not performing very well in their SGCSE physical science examination, This does not augur well for the country, because if the problem persist the girls might not be able to venture into, science related programmes at tertiary level and in the work place, as physical science is very important for admission into a wide range of academic programmes and the workplace.

Researches Igbojinwaekwu and Torunarigha (2012); Oloyede (2010), have shown that school type and gender are two of the factors influencing performance in science in the secondary schools. Hence, this study seeks to determine if there is a significant difference in the performance of girls from single sex and co - educational schools.

\section{Objectives of The Study}

The major objective of this study was: To compare the overall performance of girls in physical science in co-educational schools and those in single sex schools in Swaziland. 


\section{The Specific Objectives Were}

- To compare the performance of girls in physical science in co-educational schools and in single sex schools.

- To determine if there is any significant difference in the physical science performance of girls in co-educational and single gender schools.

- To determine factors responsible for the differences in performance of girls in physical science in co-educational and single gender schools.

\section{Research Questions}

The following research questions guided the study:

- How does the overall physical science performance of girls in co-educational schools compare with that of girls in single-sex school?

- What Is the difference in the physical science performance of girls in co-educational school and those in single-sex schools?

- What are the factors that are responsible for the differences in physical science performances of girls in co-education and single-sex schools?

\section{Hypotheses}

There is no significant difference in the physical science performance of girls in co-educational schools and single gender schools.

\section{Literature Review}

\section{Theoretical Framework}

The theories of Piaget (1896-1980), Vygotsky (1896-1934) and Bruner's (1915-present) discovery learning theory of constructivism provided the theoretical basis for the study. Piaget mentioned that children possess insufficient sensory-motor schemata or cognitive structures which provides the framework for initial interaction with the environment and which determines their early life experiences. (Ozgur, 2014; \& McLeod, 2012).

Piaget and Vygotsky believed that young children are curious and actively involved in their own learning and in the discovery and development of new understandings/schema. Taking these views along with the constructivism theory we recognise that there must be an environment, interaction and experiences for the construction of knowledge. In our case the different types of schools that is single-sex and co-educational schools provide different environments and experiences to the learners and therefore different experiences which bring different ways of constructing knowledge and thus different levels of performances.

These further inform practitioners that the school environment must be made conducive for effective learning that is enhances development of the child holistically and help them construct reasonable knowledge.

\section{Differences in Management of Single-Sex and Co-Educational Schools}

Smyth (2010) mentioned that there are difficulties associated with systematically comparison of single-sex and co-educational schools because in many countries, single-sex schools are highly selective in their social and ability profile; likewise in countries with a larger number of single-sex 
schools, the two school sectors differ in their intake. In all girls 'schools, internal competitive environment had been setup for a healthy competition whereas in the co-education schools, the cross fertilization of ideas and highly competitive environment are serious boost to high academic performance (Igbojinwaekwu \&Torunarigha, (2012).

Barineka, (2012) studied organisational climate and academic performance with reference to the school, age, management and sex, and found that younger schools were better in academic performance; unaided private schools had better position than government corporation and aided private schools in all aspects of organisational climate and academic performance moreover coeducational schools had better organisational climate aspects than single-sex schools and also the academic performance was good in these schools.

\section{Empirical Studies}

Palkhe, Hyde \& Allison (2014) analysed data from 184 studies that have tested the effects of single sex (SS) compared with Co - educational (CE) schooling. Findings from their study showed that uncontrolled studies showed some modest advantages for SS schooling for both boys and girls in mathematics but not in science. Controlled studies showed only trivial differences between students in SS and CE for mathematics and science. Moreover the Australian Council for Education Research ACER (2000) compared performances of students in single gender and coeducational schools and found that girls from single gender schools performed better than their coeducational counterparts.

Igbojinwaekwu and Torunarigha (2012) Studied academic performance of girls in single sex and co-educational schools in senior secondary schools mathematics in Delta state capital territory and found that the performance of girls in co-educational schools showed no significant difference from the performance of girls from single gender schools. The findings of this study are in disagreement with findings made by ACER (2000). who stated that girls from single gender schools outperform co-educational schools girls in sciences and mathematics. In addition Igbojinwaekwu and Torunarigha (2012) mentioned that the time interval between the undertaking of earlier studies and current studies in performance of girls might contribute to differences in the findings.

Majere, Role, and Makewa (2012) studied the performance of students on KCSE which showed that the performance gap on three districts under study on chemistry was $5 \%$ in Kiambu, $8 \%$ in Bungoma and 8.7\% in Kisumu. Thomas et al (1994) found that there was no significant difference in educational achievements of girls in co-educational school and those in single gender schools when intake differences among schools were taken into consideration.

Sullivan, Joshi, and Leonard (2011) studied single gender and co-educational schooling-life course consequences in Britain, found that for girls the gap was 14\% co-educational girls who achieved the $5^{\text {th }}$ grade or more passes compared to $47 \%$ single-sex school girls. He further suggests that factors such as prior attainment, socio-economic background and school sector are important variables to be controlled in order that results on studies give true picture of that situation.

Goldman and McCutchen (2012) in a study titled; should the sexes be separated for secondary education? Found that the overall performance of girls from single sex schools was better in GCSE 
and A level results as compared to those from co-educational schools; however this was not taking into account, the school type. In addition to their findings they mentioned that academic performance of the girl was associated with the independence state dichotomy than the nature of school either co-educational of single-sex, moreover factors like ability of intake, social class, background, history of school were closely linked to the performances.

Stromquist (2007) in a three-year study of 12 single-sex schools on account for differences in performance found that the schools have not been created on the basis of informed gender knowledge but as a way to increase school choices and diversity of public school. This view provide significant information concerning the differential in performance of the girls from the two schools, that it is not necessarily based on the type of school but other factors that are yet to be disclosed along the study.

\section{Methodology}

The study adopted a cross-sectional survey research design. This study was conducted in four high schools made up of two single - sex schools and two co-educational schools which are located in the Manzini region of Swaziland. Convenient sampling technique was used in the selection of these schools. The Manzini region is the largest region of the four regions in Swaziland and is located in the centre of Swaziland. It was chosen because the only four single - sex schools in Swaziland are located in the region. A total of 40 students randomly selected out of a population of 245 students constituted the sample for the study. The instruments for the study were a 5 -scale 10 - item Likert - type questionnaire and the SGCSE results of the selected schools for a period of five years (2009-2013). The questionnaires were personally administered by the researchers. Results were presented using tables and graphs. Data was analyzed using the Statistical Package for Social Sciences (SPSS). T-test was used to test the hypothesis at $0.05 \%$ level of significance.

\section{Results and Discussion}

Results are presented below.

Research question 1: How does the overall physical science performance of girls in co-educational schools compare with that of girls in single-sex schools?

Table 1: Summary of SGCSE physical science examination results of single-sex and coeducational schools (2008- 2012).

\begin{tabular}{|l|l|l|l|l|l|l|l|l|l|l|l|}
\hline \multirow{2}{*}{ Grade \% } & A & B & \multicolumn{1}{l}{ C } & \multicolumn{3}{|l|}{ E } & \multicolumn{2}{|c|}{ Total } \\
\cline { 2 - 14 } & Freq & \% & Freq & \% & Freq & \% & Freq & \% & Freq & \% & \\
\hline Co-educational & 16 & 1.45 & 43 & 3.89 & 64 & 5.79 & 69 & 6.25 & 105 & 9.51 & 297 \\
\hline Single-sex & 44 & 3.99 & 91 & 8.24 & 229 & 20.7 & 213 & 19.3 & 232 & 21.0 & 809 \\
\hline
\end{tabular}

Table 1 compares the results of single-sex school girls' co-educational school girls in physical science. These results show that single-sex schools perform better than co-educational schools in physical science.

Research question 2: Is there any significant difference in the physical science performance of girls in co-educational school and those in single-sex schools? 
Table 2: Summary of standard deviation and mean

\begin{tabular}{|l|l|l|l|}
\hline School type & $\mathbf{N}$ & Mean & Standard deviation \\
\hline Co-educational & 6 & 49.5 & 37.8 \\
\hline Single-sex & 6 & 134.5 & 102.4 \\
\hline
\end{tabular}

Table 2: shows a higher standard deviation of 102.4 for single-sex school which shows that the scores for single-sex schools are more widely spread than the scores from co-educational school, which have a standard deviation of 37.8. This shows that there is a significance difference in the performance of both schools, with the single-sex schools performing significantly better than coeducational schools girls.

Research question 3: What are the factors that are responsible for the differences in physical science performances of girls in co-education and single gender schools?

Table 3: Factors influencing differences in performance

\begin{tabular}{|l|l|l|l|l|l|l|l|l|l|l|}
\hline \multirow{2}{*}{ Factors } & SA & \multicolumn{3}{|l|}{ A } & UD & \multicolumn{2}{l|}{ DA } & SD \\
\cline { 2 - 10 } & Freq. & Percentage & Freq. & Percentage & Freq. & percentage & Freq. & percentage & Freq. & percentage \\
\hline $\begin{array}{l}\text { 1. Social } \\
\text { factors }\end{array}$ & 70 & $47 \%$ & 73 & $37 \%$ & 13 & $16 \%$ & 32 & $26 \%$ & 13 & $20 \%$ \\
\hline $\begin{array}{l}\text { 2. Academic } \\
\text { factors }\end{array}$ & 46 & $31 \%$ & 70 & $36 \%$ & 41 & $50 \%$ & 43 & $35 \%$ & 33 & $37 \%$ \\
\hline $\begin{array}{l}3 . \quad \text { School } \\
\text { management } \\
\text { issues }\end{array}$ & 34 & $23 \%$ & 55 & $28 \%$ & 29 & $35 \%$ & 47 & $39 \%$ & 38 & $43 \%$ \\
\hline Totals & 150 & & 198 & & 83 & & 122 & & 84 & \\
\hline
\end{tabular}

From table 3 above social factors have the greatest influence on physical science performance, followed by academic factors. School management factors have the least influence on the girl's physical science performance.

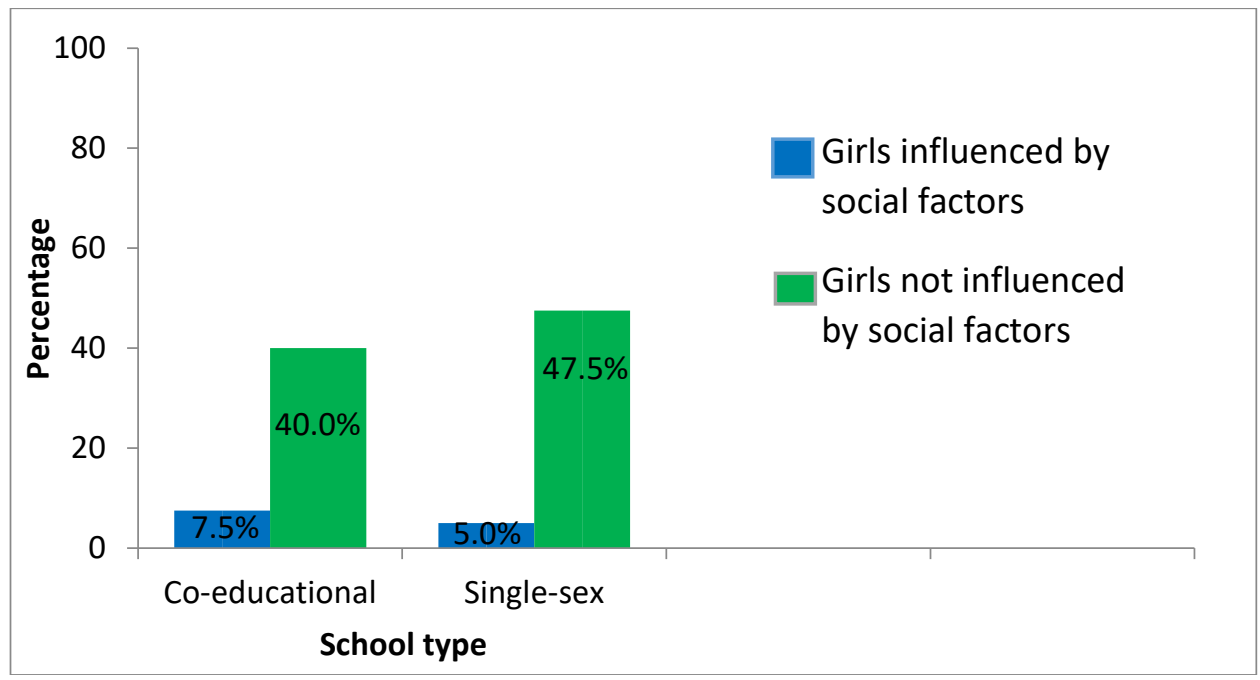

Figure 1: Influence of social factors on performance. 
Only $15 \%$ of girls from co-educational schools and $7.5 \%$ of girls from single-sex schools are influenced by social factors, such as peer pressure in their performance in physical science, as shown in figure 1 . This means in both cases social factors do not influence their physical science performance.

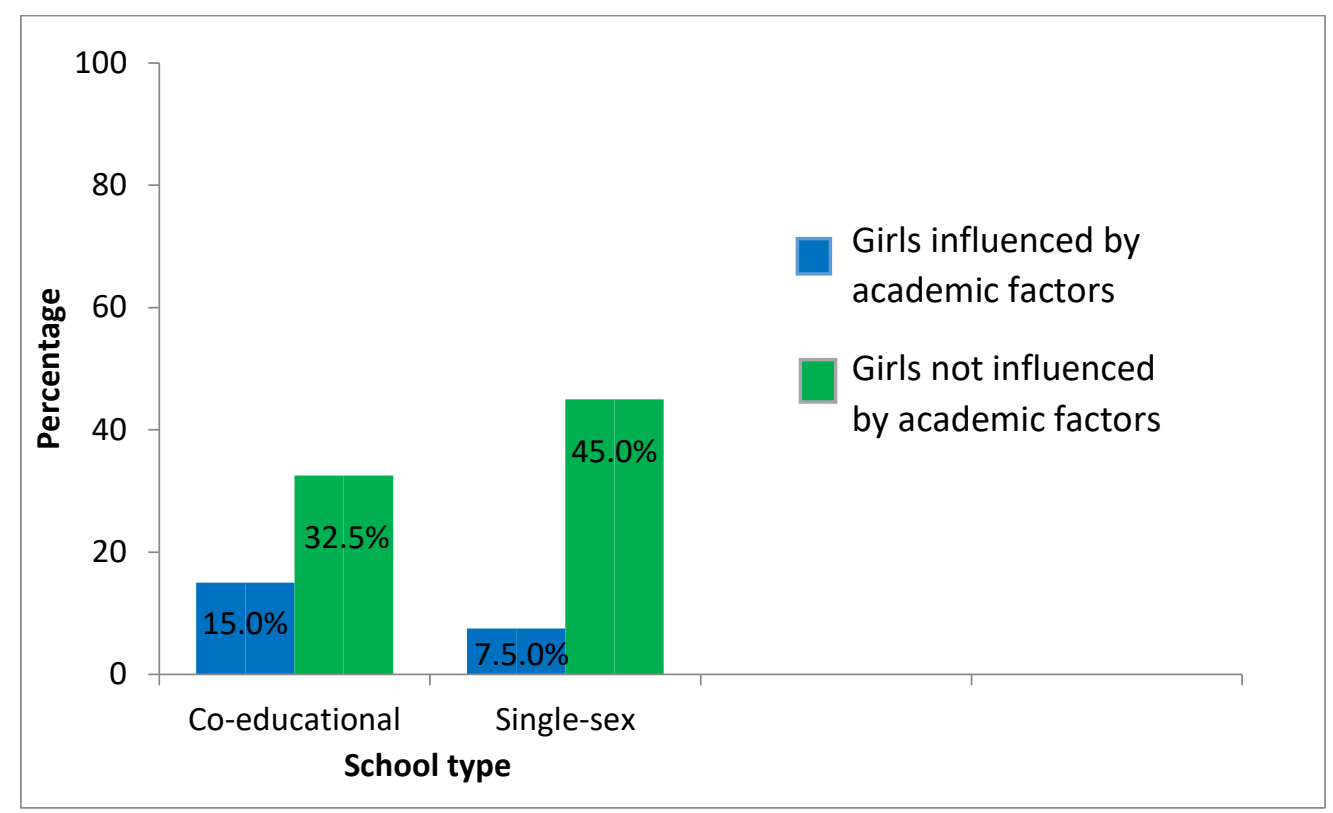

Figure 2: Influence of academic factors on performance.

Figure 2: shows that $40 \%$ of co-educational schools disagreed that their performances are influenced by academic factors, while $47 \%$ of single-sex schools disagreed that their performance is influenced by academic factors. In both cases, academic factors have less influence on the physical science performance of the girls.

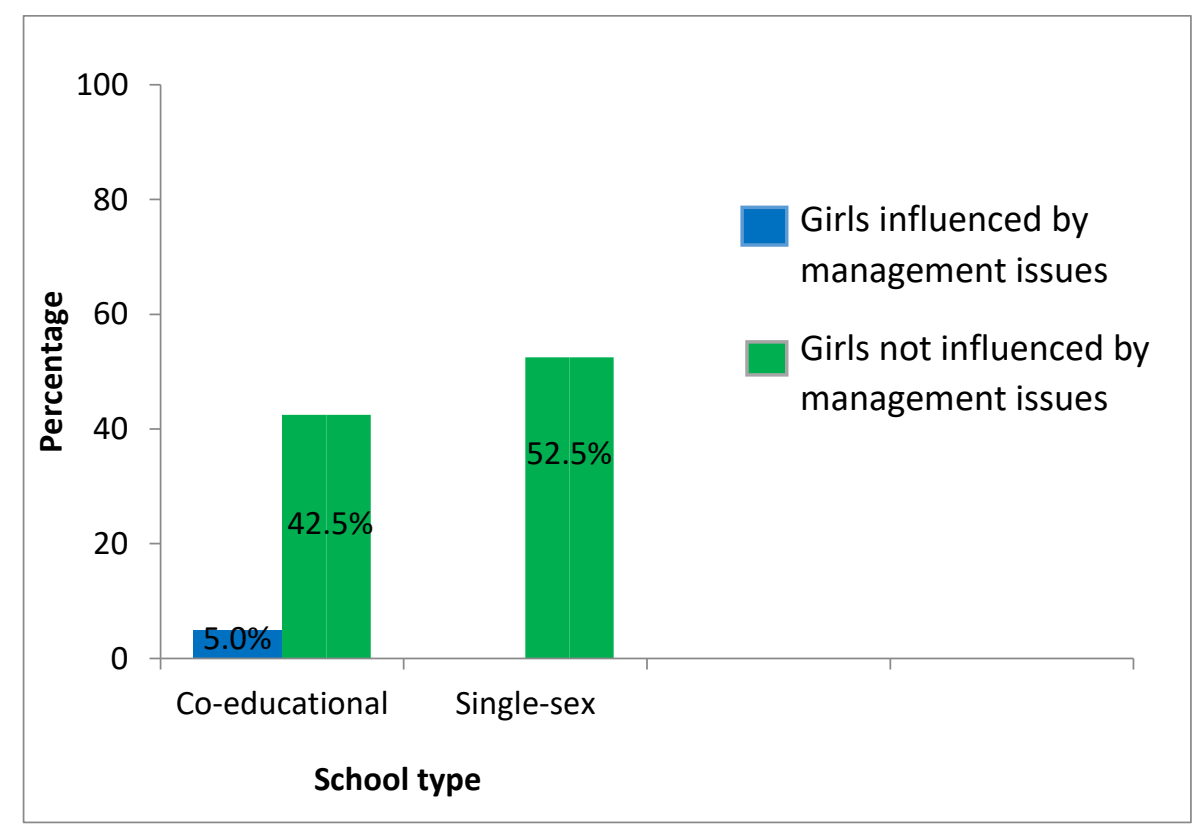

Figure 3: Influence of school management factors on performance. 
The results on figure 3 show that majority $95 \%$ of the girls in both schools agreed that school management issues have no influence on their physical science performance.

Hypotheses 1: There is no significant difference in the physical science performance of girls in coeducational schools and single gender schools.

Table 4: Summary of t-test results

\begin{tabular}{|l|l|l|l|l|l|l|l|l|}
\hline $\begin{array}{l}\text { SCHOOL } \\
\text { TYPE }\end{array}$ & N & Mean & SD & Df & t-calc & t-tab & Level of sig. & Results \\
\hline Co-education & 6 & 49.5 & 37.8 & & & & 0.05 & $\begin{array}{l}\text { Null hypothesis } \\
\text { Rejected }\end{array}$ \\
\hline Single-sex & 6 & 134.5 & 102.4 & 5 & -3.03 & 2.571 & 0.05 & \\
\hline
\end{tabular}

Table 4: shows that t-tabulated is greater than t-calculated which implies that the Null hypothesis is rejected. That means there is a significant difference between the performance of girls from single-sex school and co-educational school in physical science. The negative sign on the tcalculated value has no effect on the results obtained because it only shows that the score from single sex-school were higher than those from co-educational schools.

\section{Summary of Findings}

Below is the summary of the findings from this study:

1) Girls from single-sex schools perform better in physical science than girls from coeducational schools.

2) Single-sex schools girls perform significantly better in physical science than coeducational school girls.

3) Social factors have the greatest influence on girl's physical science performance, while school management issues have the least influence.

4) There is a significant difference in the performance of girls from co-educational schools and girls from single-sex school.

\section{Discussion}

The findings from this study showed that the overall performance of single-sex schools in physical science is better than that of co-educational schools in the Manzini region of Swaziland. These findings are in agreement with Sullivan, Joshi, \& Leonard (2011) and Amunga, Amadalo, \& Musera, (2007). The findings also showed that single-sex schools girls perform significantly better in physical science than co-educational schools girls. These results contradicts Igbojinwaekwu \&Torunarigha (2012) who studied academic performance of girls in single sex and co-educational schools in senior secondary schools mathematics in Delta state capital territory schools and found that the performance of girls in co-educational schools showed no significant difference from the performance of girls from single gender schools.

However, the researchers are of the opinion that the reasons for the difference in the performance of students in single-sex and co-educational schools may be a result of many factors not just the grades obtained after the examinations were written. Findings from Table 3 suggest that social factors have the greatest influence on girl's physical science performance while school 
management issues have the least influence. These findings are in agreement with Smyth (2012) who indicated that co-educational schools have a negative effect on girls' academic performance due to peer pressure to prioritize relations with the opposite sex rather than schoolwork. Findings also showed that in both cases, social factors have the greatest influence on the girls' physical science performance.

In both cases, academic factors have less influence on the physical science performance of the girls. These findings are in agreement with Sullivan, Joshi, \& Leonard (2011) who argues that there are many school factors that impact performance more than the gender segregation.

The findings also showed that majority (95\%) of the girls in both schools agreed that school management issues have no influence on their physical science performance. These findings agree with Amunga, Amadalo, \& Musera,(2007) who studied organizational climate and academic performance with reference to the school, age, management and sex, and found that younger schools were better in academic performance; unaided private schools had better position than government corporation and aided private schools in all aspects of organizational climate and academic performance moreover co-educational schools had better organizational climate aspects than single-sex schools and also the academic performance was good in these schools.

\section{Conclusions}

Based on the findings of this study the following conclusions were drawn:

1) Girls from single-sex schools had a better performance in physical science than girls from co-educational schools.

2) The performance of girls in single-sex schools is significantly different from the performance of girls from co-educational schools.

3) Social factors have the greatest influence on the physical science performance of girls while school management issues have the least influence.

\section{Recommendations}

From the conclusions above, it is recommended that:

1) Teachers in co-educational school should do everything possible to improve the performance of girls from their schools.

2) Teachers in single-sex schools should keep up the good work of ensuring good performance of their girls in physical science.

3) Teachers in both schools should provide guidance and counseling services in order to educate the girls on the effects of social factors such as peer pressure on their physical science performance.

\section{References}

1) Amunga, J. K. Amadalo, M. M. Musera, G. (2007). Disparities In Chemistry and Biology Achievement in Secondary Schools: Implications For Vision 2030 Muliro University of Science and Technology Kenya. International Journal of Humanities and Social Science. 1 (18). 35 - 43

2) Australian Council for Education Research (ACER) (2000) Comparing Educational performances of Single sex and Co - Educational Schools. 1120 - 1236. 
3) Barineka, J.N. (2012) Analysis of Poor Performance of Senior Secondary Students in Chemistry in Nigeria: International Multidisciplinary Journal, Ethiopia 6 (4), Serial No. 27, October, 2012, 324334.

4) Eriba, J.O and Ande, S. (2006). Gender differences in achievement in calculating reacting masses from chemical equations among secondary school students in Makurdi Metropolis: Educational Research and Reviews 1 (6), 170-173, September 2006.

5) Goldman, J.D. and McCutchen, L. E. (2012) Teenager's web questions compared with a sexuality curriculum: An Exploration. National Foundation for Educational Research. 54 (2) 2012.

6) Igbojinwaekwu, P.C. and Torunarigha, Y.D. (2012) Academic Performance of Girls in Single-sex and co-education schools in Senior School Mathematics in Delta State Capital Territory Wilberforce Island: Journal of Assertiveness 12 (2) 51 - 57

7) Majere, S.I, Role.E, and Makewa, N.L. (2012).Gender Disparities in Self-concept, Attitude and Perception in Physics and Chemistry: Atlas Journal of Science Education 2 (1): 61-69.

8) McLeod, S. A. (2012) Bruner`s three Modes of Representation. Simply Psychology. Retrieved from www.simplypsychology.org/bruner.html Retrieved 3rd March 2015

9) Oloyede, O. I. (2010) Levels of Acquisition of Science Process skills among year two senior secondary school students. UNISWA Journal of Agric., science \& Technology.13 (1)14 - 19.

10) Ozgur, O. (2014) Constructivism in Piaget \& Vgotsky. The Fountain magazine. Issue 48, 23- 25

11) Palkhe, E., Hyde, J. S. \& Allison, C. M. (2014) The Effects of single sex compared with Co Educational schooling on students' performance and attitudes: A meta - analysis. Psychological Bulletin. 140, (4) $1042-1072$.

12) Smyth, E. (2010). Single-sex Education: What Does Research Tell Us? Revue française de pédagogie 171 (2) $1102-1108$

13) Ssempala, S. R. (2005). Gender difference in performance of chemistry practical skills among senior six students in Kampal.Dissertation.com Boca Raton.

14) Stromquist.N.P. (2007). The Gender Socialization Process in Schools: A Cross-National Comparison. Education for All Global Monitoring Report 2008. 54 - 60.

15) Sullivan, A.; Joshi, H. \& Leonard, D (2011). Single sex and co - educational schooling: what are the social and family outcomes in short and long term? Longitudinal and Life Course Studies. Vol. 3 (1) $137-156$.

16) Van Zyl.G.D. (2011). A study of single-gender grouping for sixth grade mathemathics as a strategy for improving student achievement

*Corresponding author.

E-mail address: oioloyede@ uniswa.sz/vkelly@ uniswa.sz 